\title{
Cathepsin B in Eutopic and Ectopic Endometrial Tissues of Patients with Endometriosis
}

\author{
${ }^{\dagger}$ Chung-Hoon Kim${ }^{1}$, You-Jeong Lee', Jun-Bum Kim', Young-Jin Lee', Jun-Woo Ahn², \\ Sung-Hoon Kim ${ }^{1}$, Hee-Dong Chae ${ }^{1}$ and Byung-Moon Kang ${ }^{1}$ \\ ${ }^{l}$ Division of Reproductive Endocrinology and Infertility, Department of Obstetrics and Gynecology, \\ College of Medicine, University of Ulsan, Asan Medical Center, Seoul 138-736, Republic of Korea \\ ${ }^{2}$ Division of Reproductive Endocrinology and Infertility, Department of Obstetrics and Gynecology, \\ College of Medicine, University of Ulsan, Ulsan University Hospital, Ulsan 682-714, Republic of Korea
}

\begin{abstract}
This study was performed to investigate the expression of cathepsin B mRNA and protein in eutopic and ectopic endometrial tissues of patients with endometriosis and in normal endometrial tissues and to clarify the association between the cathepsin B expression and endometriosis. A total of 40 women with histologically confirmed endometriosis were recruited for study group. For controls, 20 women undergoing operative treatment for uterine myoma, cervical intraepithelial neoplasia (CIN) or benign gynecologic conditions other than endometriosis were recruited. Eutopic endometrial tissues of both groups and ectopic endometrial tissue of study group were collected during the operations. We employed real time reverse transcriptase - polymerase chain reaction (RT-PCR) to quantify mRNA levels of cathepsin B in these tissues. Then, we performed western blot analysis to measure the protein levels of cathepsin B. The expressions of cathepsin B mRNA and protein were significantly higher in both eutopic and ectopic endometrial tissues of women with endometriosis than in endometrial tissues of controls. These data suggest that the higher expression of cathepsin B in the endometrial tissues might be associated with the development of endometriosis. In addition, eutopic endometrium itself with higher expression cathepsin B may play a pivotal role in the histogenesis of endometriosis.
\end{abstract}

Key words : Endometriosis, Cathepsin B, Endometrial tissue

\section{INTRODUCTION}

Endometriosis, defined as the presence of endometrial tissue outside the uterine cavity, is one of the most common types of benign gynecological disease, occurring in about $10 \%$ of women of reproductive age and accompanied by abdominal pain, dysmenorrhea, dyspareunia, and infertility (Olive \& Schwartz, 1993; Cramer \& Missmer, 2002; D'Hooghe et al., 2003). Although endometriosis is the benign gynecological disease that raises symptoms of the pelvic pain or infertility, the correlation between precancerous pathological capacity of endometriosis and malignant tumor in the ovary or endometrium has been widely studied in that it is to be exclusive, attached to the abdominal mesothelial cell of the regurgitated endometrial tissue, invade the peritoneum, destroyed from the extracellular matrix and metastasized to around tissue, after mutation and diagnosis criteria of the malignant tumor in

\footnotetext{
Manuscript received 26 May 2013, received in revised form 10 June 2013, accepted 17 June, 2013

${ }^{\dagger}$ Corresponding Author : Chung-Hoon Kim, Division of Reproductive Endocrinology and Infertility, Department of Obstetrics and Gynecology, College of Medicine, University of Ulsan, Asan Medical Center, 88, Olympic-ro 43-gil, Songpa-gu, Seoul 138-736, Korea. Tel. : +82-2-3010-3639, Fax : +82-23010-6944, E-mail : chnkim@amc.seoul.kr

This is an Open Access article distributed under the terms of the Creative Commons Attribution Non-Commercial License(http:// creativecommons. org/licenses/by-nc/3.0) which permits unrestricted non-commercial use, distribution, and reproduction in any medium, provided the original work is properly cited.
} 
endometrium were limited in 1925 (Sampson, 1925).

Despite its frequency, the etiology and pathogenesis remain uncertain. The basic mechanism is considered with the first presented "reflux of menstrual blood" in 1927 (Sampson, 1927), the complex influence of the genetic and immune biological factors happens to endometriosis with implantation of the survival endometrium. Endometriosis is observed in the reflux of menstrual blood of over 90\% reproductive-aged women (Halme et al., 1984). However, it is difficult to explain that endometriosis is only caused by the reflux of menstrual blood, because endometriosis actually occurs in $10 \%$ of reproductive aged women and extra-abdominal endometriosis is reported. For the development of endometriosis, ectopic endometrial tissue should get the survival chance in the abdominal cavity, so that the refluxed endometrial tissue in the abdominal cavity is not normally removed out or absorbed by immune factor. Whatever happens of either genetic or biologic cause, endometrial tissue of endometriosis patient has to overcome the normal immune mechanism inside the abdominal cavity. The remained endometrial tissue inside the abdominal cavity can be implanted in peritoneum through adhesion and invasion. So endometriosis takes place by the several processes. Based on these suggestions, expression and activity of the adhesion material, protease enzyme, and angiogenesis materials have been compared and analyzed between the endometrial tissue of endometriosis patients and normal women.

Cathepsin B, lysosomal cysteine protease of the papain family, dissolves collagen, laminin, fibronectin and proteoglycan (Schmitt et al., 1991; Eeckhout \& Vaes, 1997). Cathepsin B relates with bone resorption by activation of the resorption-relating other enzymes, the calcium homeostasis in bone and production of thyroid hormone through thyroglobulin degradation (Mort \& Buttle, 1997), but the major role of cathepsin $\mathrm{B}$ is to dissolve protein included in lysosomal system by phagocytosis, endocytosis, autophagy (Bohley \& Seglen, 1992). It have been reported that catepsin B activates trypsin in acute pacreatitis and hydrolyzes the interstitium components, epithelial basement membrane, cartilaginous bronchial and tracheal rings with bronchiectasis and neutrophil elastase of bronchitis (Mort \& Buttle, 1997). In addition, activating metalloproteinase degrading proteoglycan and type II collagen in arthritis disease and leading hepatocyte apoptosis to be mediated by TNF- $\alpha$ (Guicciardi et al., 2000). The secretion of Cathepsin B was increased at the edges of human malignant breast carcinomas compared to benign (Poole et al., 1980), and in human prostate including invasive cells cathepsin B expression was increased (Sinha et al., 1993). Also, cathepsin B expression was related to human colorectal (Murnane et al., 1991) and glial carcinoma (Rempel et al., 1994). Cathepsin B is expressed in most mammalian cells and secreted in endometrium. Also, treatment with cathepsin $\mathrm{B}$ inhibitor prohibit estrogeninduced membrane alteration in endometrium (Pietra \& Szego, 1979).

If cathepsin B that can regulate cell adhesion, estrogeninduced cell proliferation and extracellular lysis is expressed highly in human endometriosis tissues, it can be a good contributing factor for the development and progression of endometriosis. Therefore, this study was performed to investigate the expression of cathepsin $\mathrm{B}$ mRNA and protein in the eutopic and ectopic endometrial tissues of women with endometriosis. and endometrial tissues with endometriosis and to clarify the association between the cathepsin B and endometriosis.

\section{MATERIAL AND METHODS}

\section{Patients}

\section{1) Endometriosis group}

In the endometriosis group, the extent of disease was staged according to the American Society for Reproductive Medicine. Patients who had pelvic inflammatory disease, dysfunctional uterine bleeding, or any endometrial pathology, and who had been suspected of having endometriotic lesions only by laparoscopic inspection without 
Table 1. Patients' characteristics

\begin{tabular}{lcc}
\hline \hline & Control group & Study group \\
\hline Patients (n) & 20 & 40 \\
Age (years) (range) & $34.9 \pm 5.2^{*}$ & $35.8 \pm 6.0^{*}$ \\
Parity & $(23-45)$ & $(23-45)$ \\
No. of associated disease (\%) & $1.5 \pm 0.7$ & $0.9 \pm 0.9$ \\
Leiomyoma & $10(50.0)$ & $7(17.5)$ \\
Benign ovarian cyst & $7(35.0)$ & 0 \\
CIN & $3(15.0)$ & 0 \\
Proliferative phase (n) & 10 & 19 \\
Mid-secretory phase (n) & 10 & 21 \\
\hline
\end{tabular}

* Means \pm SD.

histological confirmation were excluded from this study. A total of 40 patients had histological and laparoscopic evidence of advanced stage endometriosis (stage III or IV), and had regular menstrual cycles and had not received any hormonal therapy during the previous 6 months. The Institutional Review Board of our center approved the study and all patients provided written informed consent. Patients' characteristics were shown in Table 1.

\section{2) Control group}

Among patients with treatment of operation due to positive gynecological diseases or cervical intraepithelial neoplasia (CIN) in Asan Medical Center, 20 patients with proven fertility without the endometriosis served as controls.

\section{Preparation of endometrial tissues}

Endometrial samples were obtained either by using a curette after pelviscopy or by opening the uterine cavity immediately after hysterectomy. Tissues used for mRNA extraction were snap-frozen in liquid nitrogen and stored at $-70^{\circ} \mathrm{C}$ until analyzed. All tissues were dated by a gynecological pathologist according to the histological criteria and were classified as early proliferative (days 4-7), mid proliferative (days 8-10), late proliferative (days 11-14), early secretory (days 15-18), mid secretory (days 19-22) or late secretory (days 23-28) phases.
3. Real-time reverse transcription-polymerase chain reaction (RT-PCR)

Total RNA was isolated using Trizol reagent (Life Technologies Inc, Rockville, MD, USA) according to the manufacturer's protocol. Briefly, endometrial tissue was homogenized in $1 \mathrm{ml}$ of Trizol. Chloroform (200 $\mu \mathrm{l})$ was added, and the solution was incubated at room temperature for $3 \mathrm{~min}$ and centrifuged at $12,000 \mathrm{~g}$ for 15 $\min$ at $4{ }^{\circ} \mathrm{C}$. The upper aqueous phase was incubated with $500 \mu \mathrm{l}$ isopropanolol at room temperature for $10 \mathrm{~min}$ and centrifuged at $11,000 \mathrm{~g}$ for $10 \mathrm{~min}$. The RNA pellet was washed in $75 \%$ ethanol and centrifuged at $7,500 \mathrm{~g}$ for $5 \mathrm{~min}$. The resulting pellet was dried and resuspended in diethylpyrocarbonate (DEPC)-treated water (SigmaAldrich, St. Louis, MO, USA) and stored at $-70^{\circ} \mathrm{C}$. The concentration of RNA was determined on a spectrophotometer (GeneQuant pro, Amersham Phamarcia Biotech, USA). RT was performed using the Promega Reverse Transcription System (Promega, Madison, WI, USA). Eighteen microliters of RT-master mix for each sample were prepared, containing $5 \mathrm{mmol} / 1$ of $\mathrm{MgCl}_{2}$, reverse transcription buffer, $1 \mathrm{mmol} / 1$ of each deoxy-NTP, $0.5 \mu \mathrm{g}$ oligo (deoxythymidine) 15 primers, $20 \mathrm{IU}$ of ribonuclease inhibitor, 15 units of AMV reverse transcriptase, and 1 $\mu \mathrm{g}$ of total RNA diluted in $2 \mu \mathrm{l}$ of DEPC-treated $\mathrm{H}_{2} \mathrm{O}$. Each sample was placed in a $0.5-\mathrm{ml}$ microtube, and reverse transcription was carried out in the thermocycler (GeneAmp 9700, Applied Biosystems, Foster City, CA) for 60 minutes at $42^{\circ} \mathrm{C}$ and 5 minutes at $90^{\circ} \mathrm{C}$, with quenching at $4{ }^{\circ} \mathrm{C}$. The samples were stored at $-20^{\circ} \mathrm{C}$ until PCR. Real-time PCR was carried out on approximately 50 ng cDNA utilizing an ABI 7000 Sequence Detection System apparatus (Applied Biosystems, Foster City, CA) in a 20- $\mu 1$ volume containing $1 \mathrm{X}$ SYBR Green PCR master mix (Applied Biosystems) and 10 pmole of the forward and reverse primers. All samples were assayed in triplicate, and each aliquot was transferred to wells of a MicroAmp optical 96-well reaction plate (Applied Biosystems). The thermocycler parameters were $50^{\circ} \mathrm{C}$ for $2 \mathrm{~min}$ and $10 \mathrm{~min}$ at $95^{\circ} \mathrm{C}$, followed by 40 cycles of 15 
Table 2. Primer sequences for RT-PCR

\begin{tabular}{cl}
\hline \hline Gene & \multicolumn{1}{c}{ Forward and reverse primer sequence } \\
\hline \multirow{2}{*}{ GAPDH } & $\begin{array}{l}\text { Forward : 5'-GCTGTGGGCAAGGTCATCC-3' } \\
\text { Reverse : 5'-CTTGCTGGGGCTGGTGGTC-3' }\end{array}$ \\
\hline \multirow{2}{*}{-Actin } & $\begin{array}{l}\text { Forward : 5'-GTGGGCCGCTCTAGGCACCAA-3' } \\
\text { Reverse : 5'-CTCTTTGATGTCACGCACGATTC-3' }\end{array}$ \\
\hline \multirow{2}{*}{ Cathepsin B B Forward : 5'-TCGGATGAGCTGGTCAACTATG-3' } \\
& Reverse : 5'-TCCAAGCTTCAGCAGGATAG-3' \\
\hline
\end{tabular}

GAPDH : glyceraldehyde-3-phosphate dehydrogenase

RT-PCR : reverse transcriptase-polymerase chain reaction

sec at $95^{\circ} \mathrm{C}$ and $1 \mathrm{~min}$ at $60^{\circ} \mathrm{C}$. Primers used for real-time PCR were listed in Table 2. The expression of each target gene was normalized to the expression of the control gene (hGAPDH).

\section{Western blotting}

Well-demolished tissues were lysed in Triton X-100 lysis buffer (1\% Triton X-100, $1 \mathrm{mM}$ EDTA, $150 \mathrm{mM}$ $\mathrm{NaCl}, 50 \mathrm{mM} \mathrm{NaF}$, and a protease inhibitor mixture; Calbiochem, Darmstadt, Germany), and insoluble materials were precipitated by centrifugation at $16,000 \times \mathrm{g}$ for $10 \mathrm{~min}$ at $4^{\circ} \mathrm{C}$. The supernatant was transferred to a new tube and protein concentrations were determined by using a protein assay dye reagent (Bio-Rad, Hercules, CA) according to the manufacturer's recommendations. Twelve micrograms of each lysate was resolved by $12 \%$ sodium dodecyl sulfate-polyacrylamide gel electrophoresis (SDS-PAGE), transferred to a nitrocellulose membrane, and then immunoblotted with anti-Cathepsin B (R\&D systems, MN or anti-Beta-actin (Sigma-aldrich, USA) antibody. Binding of primary antibodies was detected by incubating blots with horseradish-peroxidase-conjugated goat antirabbit or antimouse antibody, and blots were developed using enhanced chemiluminescence (Western blotting detection reagents; Amersham Biosciences, Piscataway, NJ).

\section{Statistical analysis}

The mean value was expressed as the mean \pm standard deviation (SD). Student's $t$-test and Mann-Whitney $U$ test with Bonferoni correction was used to compare the mean values between the two groups. Kruskal-Wallis test was used to compare the mean values among three groups. Statistical significance was defined as $P<0.05$. All analyses were performed using the SPSS statistical package for Windows, ver. 12.0 (SPSS Inc, Chicago, IL, USA).

\section{RESULTS}

\section{Expression of cathepsin $B$ mRNA in endometrial} tissues in proliferative and mid-secretory phase of the menstrual cycle in endometriosis patients and controls

Cathepsin B mRNA was detected not only in the eutopic and ectopic endometrial tissues of patients with stage III or IV endometriosis but also endometrial tissue of controls. When compared the relative amount of cathepsin B mRNA beween proliferative phase and midsecretory phase in each eutopic and ectopic endometrial tissues of endometriosis patients and endometrial tissue of controls, cathepsin B mRNA levels seemed to be higher in the endometrium of proliferative phase than mid-secretory phase in all 3 kinds of endometrial tissues, but the all differences did not achieve the statistical significance (Fig. 1).

\section{Expression of cathepsin B mRNA in eutopic} endometrium of endometriosis patients and eutopic endometrium of controls

Expression levels of cathepsin B mRNA were significantly higher in eutopic endometrium of endometriosis patients than in eutopic endometrium of control women ( $p=0.007$ ) (Fig. 2). When cathepsin B mRNA levels were

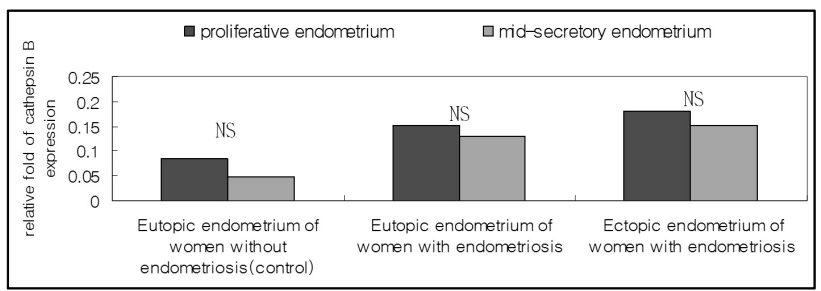

Fig. 1. Expression of cathepsin B mRNA in endometrial tissues in proliferative and mid-secretory phase of menstrual cycle in endometriosis patients and controls. 


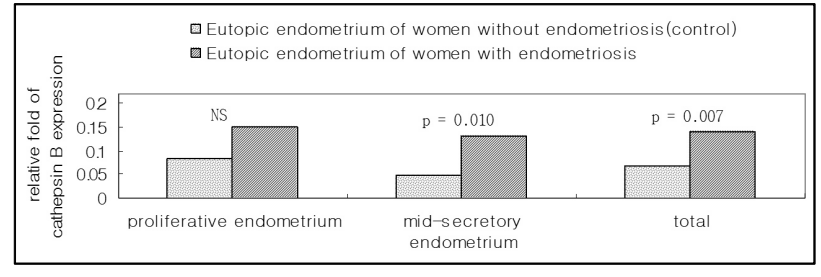

Fig. 2. Expression of cathepsin B mRNA in endometrial tissue of controls and eutopic endometrium of endometriosis patients.

compared in each endometrium of proliferative phase and mid-secretory phase, cathepsin B mRNA levels in eutopic mid-secretory endometrium were significantly higher in endometriosis patients $(p=0.010)$ but there is no significant difference in its levels in eutopic proliferative endometrium between endometriosis and control women (Fig. 2).

\section{Expression of cathepsin B mRNA in ectopic} endometrial tissue of endometriosis patients and eutopic endometrium of controls

Cathepsin B mRNA levels were significantly higher in ectopic endometrium of endometriosis patients than in eutopic endometrium of control women $(p=0.009)$ (Fig. 3). When cathepsin B mRNA levels were compared according to the menstrual phase, cathepsin $\mathrm{B}$ mRNA levels in ectopic endometrium of endometriosis patients in both proliferative and mid-secretory phase were significantly higher, compared with eutopic endometrium of controls ( $p=0.043, p=0.021$, respectively) (Fig. 3).

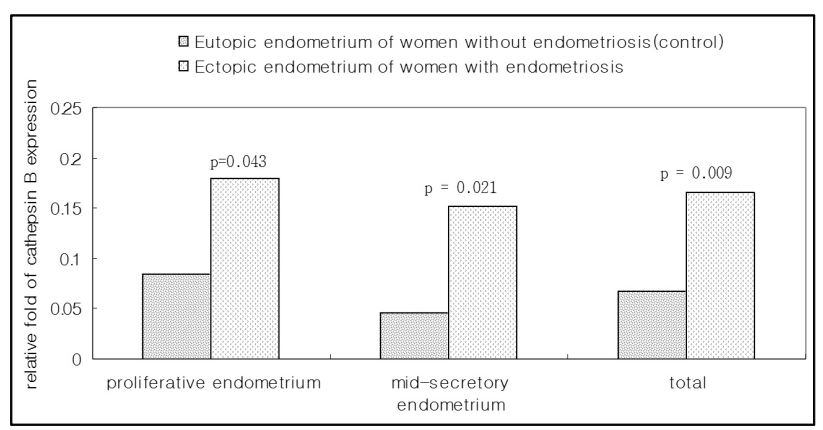

Fig. 3. Expression of cathepsin B mRNA in endometrium of control group and ectopic endometrium of endometriosis patients.

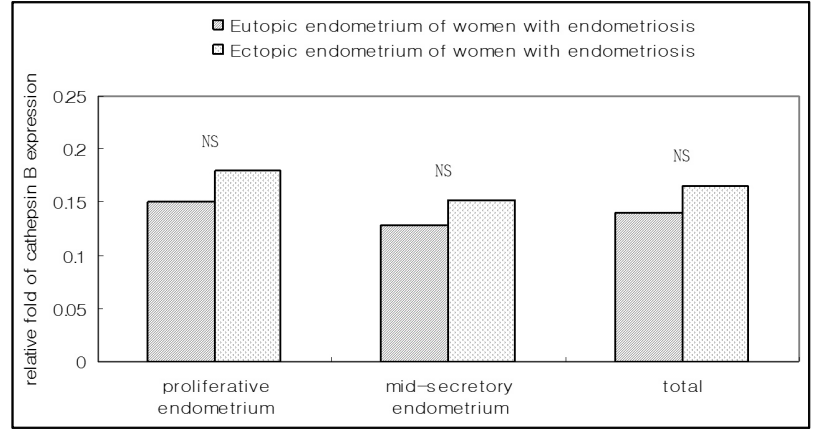

Fig. 4. Expression of cathepsin B mRNA in eutopic and ectopic endometrium of endometriosis patients.

4. Expression of cathepsin B mRNA in eutopic and ectopic endometrium of endometriosis patients

Cathepsin B mRNA levels were comparable between eutopic and ectopic endometrium of endometriosis patients in both phases of the menstrual cycle (Fig. 4).

5. Expression of cathepsin B protein in eutopic and ectopic endometrium of endometriosis patients and eutopic endometrium of control women

Cathepsin B protein levels were higher in ectopic and eutopic endometrium of endometriosis patients in proliferative phase and also higher in ectopic endometrium of endometriosis patients in mid-secretary phases, compared with controls (Fig. 5A and B).

\section{DISCUSSION}

In this study, we investigated the expression of cathepsin B mRNA and protein in eutopic and ectopic endometrial tissues of endometriosis patients, compared with controls. The present study showed that expression of cathepsin B mRNA and protein was increased in eutopic and ectopic endometrial tissues of endometriosis patients and especially in the mid-secretary phase of the menstrual cycle. These results suggest that cathepsin B can be one of the factors affecting endometriosis development.

Cathepsin B mRNA levels were lower in mid-secretary phase than the proliferative phase of the menstrual cycle. It has been also demonstrated that cathepsin B expression 

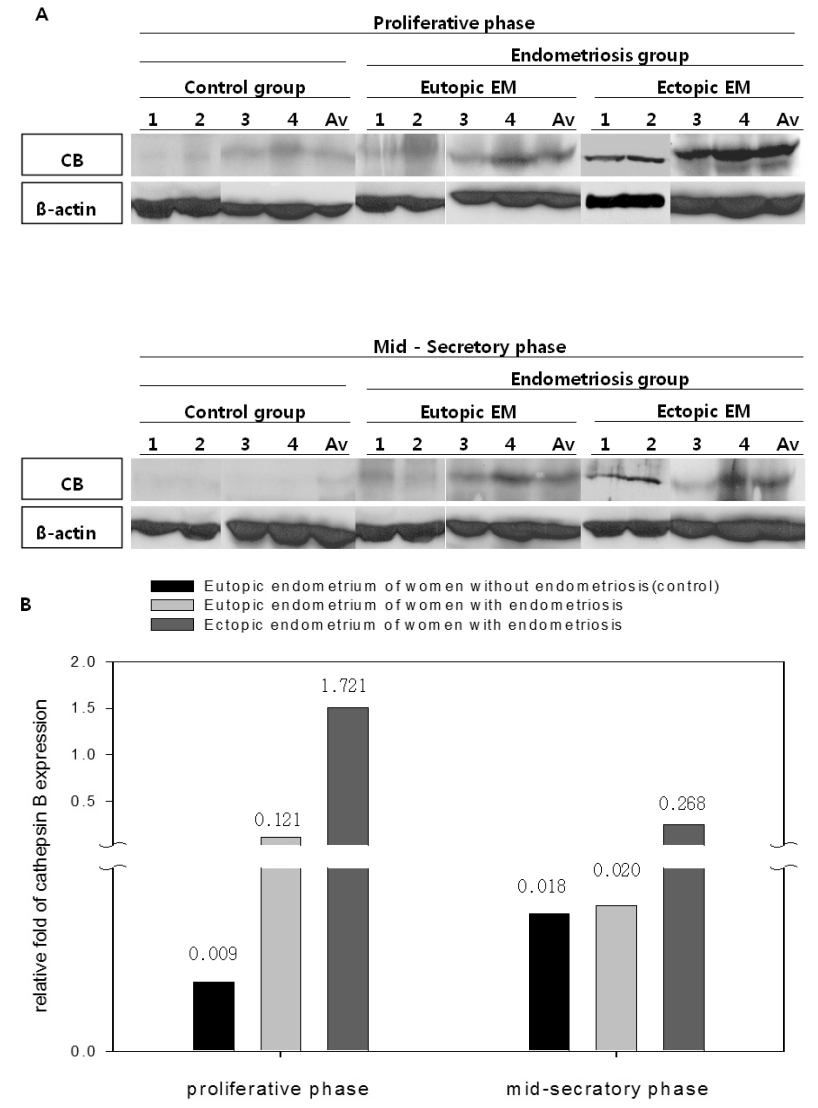

Fig. 5. Expression of cathepsin B protein in endometrium of controls and eutopic and ectopic endometrium of endometriosis patients. (A) Representative western blot analysis. (Av: average, CB: cathepsin B), (B) Expression of cathepsin $\mathrm{B}$ protein in endometrium of controls and eutopic and ectopic endometrium of endometriosis patients. B. Quantification of cathepsin B protein levels.

is the peak in the late follicular phase, and then is decreased at the ovulatory and luteal phase in the rat ovary (Oksjoki et al., 2001). Cathepsin B may be related with destruction of follicle and it is predominantly expressed on the site contacting with germinal epithelium of follicle (Oksjoki et al., 2001). Jokinaa et al (2001) reported that cathepsin B amount was not significantly changed in endometrial tissues during proliferative phase to secretary phase. They also reported that passing from the proliferative phase to secretary phase, the distribution of cathepsin B mRNA in endometrial gland altered to the apex of cell, therefore cathepsin B expression was regulated by the intracellular or tissue local transformation rather than the expression quantity in the menstrual cycle (Jokinaa et al., 2001). The intracellular local transformation represents that cathepsin B normally existed into lysosome around the nucleus, and was also observed and recreated in vesicular compartment near the tumor cell (Mai et al., 2000).

Cathepsin D, aspartyl protease, was increased in endometriosis lesion and was the peak at the luteal phase in ovarian lesion (Bergqvist et al., 1996). Cathepsin D expression was correlated with estrogen, also increased in ascites of endometriosis patients, and there was no variation by menstrual cycle (Suzumori et al., 2001). In addition, cathepsin D was increased in an advanced stages of endometriosis and accelerated protease causing degradation of the basement membrane and the extracellular matrix, so that cathepsin D can regulate invasiveness and metastasis of tumor cells and development and proliferation of endometriosis (Suzumori et al., 2001). In the present study, we found that expression of cathepsin B was significantly increased in eutopic as well as ectopic endometrium of endometriosis patients compared with women without endometriosis. Thus, we assume that the continuous increase of cathepsin B in eutopic and ectopic endometrium of endometriosis patients can contribute to the implantation and development of ectopic endometrial tissue into the abdominal cavity or any other place of human body.

Secretion of cathepsin B was increased by estrogen in mouse uterus and ovary (Pietras \& Szego, 1975) and it was mediated by estrogen receptor- $\beta$ (Pietra \& Szego, 1979; Gaido et al., 1999). However, expression rate of estrogen receptor- $\beta$ was not affect by the menstrual cycle (Hudelist et al., 2005). Also, regulation of cathepsin B was not correlated with progesterone concentration (Irwin et al., 1996). Therefore, expression of cathepsin $\mathrm{B}$ appears to have no concern with the menstrual cycle. Although endometriosis was common in women, little is known about the pathological understanding for this disease. To understand its pathological mechanisms, molecular dissection of activities for steroid hormones, these receptors, 
immune systems as well as relationship with ectopic endometrium are required (Hastings \& Fazleabas, 2003).

In conclusion, expression of cathepsin B is not correlated with the menstrual cycle and the over-expressed cathepsin B contributes to endometriosis development. In case of endometriosis patients, eutopic endometrium itself may play an important role in implantation and development of ectopic endometrial tissue. Therefore, we suggest that cathepsin B may be concerned about invasion and translocation of endometrial tissue into the ectopic sites for endometriosis development.

\section{REFERENCES}

Bergqvist A, Ferno M, Mattson S (1996) A comparison of cathepsin D levels in endometriotic tissue and in uterine endometrium. Fertil Steril 65:1130-1134.

Bohley P, Seglen PO (1992) Proteases and proteolysis in the lysosome. Experientia 48:151-157.

Cramer DW, Missmer SA (2002) The epidemiology of endometriosis. Ann N Y Acad Sci 955:11-22.

D’Hooghe TM, Debrock S, Hill JA, Meuleman C (2003) Endometriosis and subfertility: is the relationship resolved? Semin Reprod Med 21:243-254.

Eeckhout Y, Vaes G (1997) Further studies on the activation of procollagenase, the latent precursor of bone collagenase. Effects of lysosomal cathepsin B, plamin and kallikrein, and spontaneous activation. Biochem $\mathrm{J}$ 166:21-31.

Gaido KW, leonard LS, Maness SC, Hall JM, McDonnell D, Saville B (1999) Differential interaction of the methoxychlor metabolite 2,2-bis-(p-hydroxyphenyl)1,1,1-trichloroethane with estrogen receptors $\alpha$ and $\beta$. Endocrinology 140:5746-5753.

Goldman MB, Cramer DW (1989) Current concepts in endometriosis. Prog Clin Biol Res 323:17-23.

Guicciardi ME, Deussing J, Miyoshi H, Bronk SF, Svingn PA, Peters C, et al (2000) Cathepsin B contributes to TNF- $\alpha$-mediated hapatocyte apoptosis by promoting mitochondrial release of cytochrome $\mathrm{c}$.
J Clin Invest 106:1127-1137.

Halme J, Hammond MG, Hulka JF, Raj SG, Talbert LM (1984) Retrograde menstruation in healthy women and in patients with endometriosis. Obstet Gynecol 64:151-154.

Hastings JM, Fazleabas AT (2003) Future directions in endometriosis research. Semin Reprod Med 21: 255-262.

Hudelist G, Keckstein J, Czerwenka K, Lass H, Walter I, Auer M (2005) Estrogen receptor $\beta$ and matrix metalloproteinase 1 are coexpressed in uterine endometrium and endometriotic lesions of patients with endometriosis. Fertil Steril 84(supl2):1249-1256.

Irwin JC, Kirk D, Gwatkin RB, Navre M, Cannon P, Giudice LC (1996) Human endometrial matrix metalloproteinase-2, a putative menstrual proteinase. Hormonal regulation in cultured stromal cells and messenger RNA expression during the menstrual cycle. J Clin Invest 97:438-447.

Jokimaa V, Oksjoki S, Kujari H, Vuorio E, Anttila L (2001) Expression patterns of cathepsins B, H, K, L and $\mathrm{S}$ in the human endometrium. Mol Human Reprod 7:73-78.

Mai J, Waisman DM, Sloane BF (2000) Cell surface complex of cathepsin B/annexin II tetramer in malignant progression. Biochem Biophysic Acta 1477:215-230.

Mort JS, Buttle DJ (1997) Cathepsin B. Int J Biochem Cell Biol 29:715-720.

Murnane MJ, Sheahan K, Ozdemirli M, Shuja S (1991) Stage-specific increases in cathepsion B messenger RNA content in human colorectal carcinoma. Cancer Res 51:1137-1142.

Oksjoki S, Soderstrom M, Vuorio E, Anttila L (2001) Differential expression patterns of cathepsins B, H, $\mathrm{K}, \mathrm{L}$ and $\mathrm{S}$ in the mouse ovary. Mol Hum Reprod 7:27-34.

Olive DL, Schwartz LB (1993) Endometriosis. N Engl J Med 328:1759-1769.

Pietra RJ, Szego CM (1979) Estrogen-induced membrane alterations and growth associated with proteinae activity 
in endometrial cells. Cell Biol 81:649-663.

Pietras RJ, Szego CM (1975) Surface modifications evoked by estradiol and diethylstilbestrol in isolated endometrial cells: Evidence from lectin robes and extracellular release of lysosomal protease. Endocrinology 97:1445-1454.

Poole AR, Tiltman KJ, Recklies AD, Stoker TA (1980) Differences in the secretion of the proteinase cathepsin $B$ at the edges of human breast carcinomas and fibroadenomas. Nature 273:545-547.

Rempel SA, Rosenblum ML, Mikkelsen T, Yan PS, Ellis KD, Golembieski WA (1994) Cathepsin B expression and localization in glioma progression and invasion. Cancer Res 54:6027-6031.

Sampson JA (1925) Endometrial carcinoma of the ovary arising in endometrial tissue in that organ. Arch Surg 10:1-72.
Sampson JA (1927) Peritoneal endometriosis due to the menstrual dissemination of endometrial tissue into the peritoneal cavity. Am J Obstet Gynecol 14:422-469. Schmitt M, Goretzki L, Janicke F, Calvete J, Eulitz M, Kobayashi H, et al (1991) Biological and clinical relevance of the urokinase-type plasminogen activator (uPA) in breast cancer. Biomed Biochim Acta 50: 731-741.

Sinha AA, Gleason DF, DeLeon OF, Wilson MJ, Sloane BF (1993) Localization of a biotinylated cathepsin B oligonucleotide probe in human prostate including invasive cells and invasive edges by in situ hybridization. Anat Rec 235:233-240.

Suzumori N, Ozaki Y, Ogasawara M, Suzumori K (2001) Increased concentrations of cathepsin D in peritoneal fluid from women with endometriosis. Mole Human Reprod 7:459-462. 